OPEN ACCESS

Edited by:

Vicenta Salvador Recatala, Ronin Institute, United States

Reviewed by:

Alexandra C. U. Furch,

Friedrich-Schiller-Universität Jena,

Germany

Yutaka Miyazawa,

Yamagata University, Japan

*Correspondence:

Maria Stolarz

maria.stolarz@poczta.umcs.lublin.p

Specialty section:

This article was submitted to

Plant Physiology,

a section of the journal

Frontiers in Plant Science

Received: 21 June 2017 Accepted: 27 September 2017 Published: 18 October 2017

Citation:

Stolarz M and Dziubinska H (2017) Osmotic and Salt Stresses Modulate Spontaneous and Glutamate-Induced

Action Potentials and Distinguish between Growth and Circumnutation in Helianthus annuus Seedlings. Front. Plant Sci. 8:1766 doi: 10.3389/fp/s.2017.01766

\section{Osmotic and Salt Stresses Modulate Spontaneous and Glutamate-Induced Action Potentials and Distinguish between Growth and Circumnutation in Helianthus annuus Seedlings}

\author{
Maria Stolarz* and Halina Dziubinska \\ Department of Biophysics, Institute of Biology and Biochemistry, Maria Curie-Skłodowska University, Lublin, Poland
}

Action potentials (APs), i.e., long-distance electrical signals, and circumnutations (CN), i.e., endogenous plant organ movements, are shaped by ion fluxes and content in excitable and motor tissues. The appearance of APs and CN as well as growth parameters in seedlings and 3-week old plants of Helianthus annuus treated with osmotic and salt stress (0-500 mOsm) were studied. Time-lapse photography and extracellular measurements of electrical potential changes were performed. The hypocotyl length was strongly reduced by the osmotic and salt stress. CN intensity declined due to the osmotic but not salt stress. The period of $\mathrm{CN}$ in mild salt stress was similar to the control ( $164 \mathrm{~min}$ ) and increased to more than $200 \mathrm{~min}$ in osmotic stress. In sunflower seedlings growing in a hydroponic medium, spontaneous APs (SAPs) propagating basipetally and acropetally with a velocity of $12-20 \mathrm{~cm} \mathrm{~min}^{-1}$ were observed. The number of SAPs increased 2-3 times (7-10 SAPs $24 \mathrm{~h}^{-1}$ plant $^{-1}$ ) in the mild salt stress $(160 \mathrm{mOsm} \mathrm{NaCl}$ and $\mathrm{KCl}$ ), compared to the control and strong salt stress (3-4 SAPs $24 \mathrm{~h}^{-1}$ plant $^{-1}$ in the control and $300 \mathrm{mOsm} \mathrm{KCl}$ and $\mathrm{NaCl}$ ). Glutamate-induced series of APs were inhibited in the strong salt stress-treated seedlings but not at the mild salt stress and osmotic stress. Additionally, in 3-week old plants, the injection of the hypo- or hyperosmotic solution at the base of the sunflower stem evoked series of APs (3-24 APs) transmitted along the stem. It has been shown that osmotic and salt stresses modulate differently hypocotyl growth and $\mathrm{CN}$ and have an effect on spontaneous and evoked APs in sunflower seedlings. We suggested that potassium, sodium, and chloride ions at stress concentrations in the nutrient medium modulate sunflower excitability and $\mathrm{CN}$.

Keywords: osmotic potential, salt stress, circumnutation, plant movement, electrophysiology, action potential, electrical transmission, signaling

\section{INTRODUCTION}

Responses to stress and stimuli are essential for adaptation of organisms to environmental conditions. The role of signals propagated along plants organ and organ movements in these responses is an intriguing question. Universal electrical signals, i.e., action potentials (APs) propagating acropetally and basipetally many centimeters along plant organs from cell to cell 
are well-documented. Complete electrophysiological characterization of APs (threshold, refractory periods, "allor-none" law, velocity of propagation, chronaxie, reobase) has been carried out for Helianthus annuus, Lupinus angustifolius, and Conocephalum conicum (Paszewski and Zawadzki, 1973, 1974, 1976a,b; Zawadzki, 1979, 1980; Zawadzki et al., 1991, 1995; Favre et al., 1999). It is known that APs are involved in rapid plant movement and regulate many physiological processes and the circumstances of their appearance are still studied (Sibaoka, 1991; Stankovic et al., 1998; Dziubinska, 2003; Stahlberg et al., 2006; Zimmermann et al., 2009, 2016; Król et al., 2010; Stolarz et al., 2010; Salvador-Recatala et al., 2014; van Bel et al., 2014; Kiep et al., 2015; Macedo et al., 2015; Salvador-Recatala and Tjallingii, 2015; Hedrich et al., 2016; Salvador-Recatala, 2016). A spontaneous action potential (SAP) is an action potential in which exogenous or endogenous stimuli evoking them are not known. Usually, in plants, APs result from an external stimulus (Paszewski and Zawadzki, 1973; Trebacz and Zawadzki, 1985; Favre et al., 1999; Krol et al., 2006; Król et al., 2010). However, some excitable cells do not require stimuli for generation of APs (Zawadzki et al., 1995). They spontaneously depolarize and generate an AP usually at a regular rate/rhythm. This SAP rate/rhythm can be adjusted by environmental condition as was shown recently in H. annuus (Stolarz and Dziubinska, 2017). The external stimuli or environmental conditions do not cause SAPs, but merely alter their rate/rhythm. In plants, SAPs were described over 20 years ago by Zawadzki et al. (1995) in H. annuus and lately they have been observed in Solanum lycopersicum plants (Macedo et al., 2015). The AP ion mechanism in plants has been elaborated in many species, for example C. conicum, Arabidopsis thaliana, and Physcomytrella patens (Trebacz and Zawadzki, 1985; Trebacz et al., 1989, 1994, 2007; Trebacz, 1992; Krol et al., 2006, 2007; Koselski et al., 2015, 2017). Fundamental players in the AP ion mechanism in plants are $\mathrm{H}^{+}, \mathrm{Ca}^{2+}, \mathrm{K}^{+}$, and $\mathrm{Cl}^{-}$. The latter ones $\left(\mathrm{K}^{+}\right.$and $\left.\mathrm{Cl}^{-}\right)$are also the major osmotically active elements in the cytoplasm and vacuole and are involved in both osmoregulation and turgor maintenance and thus water fluxes and cell volume changes (White, 2001; Zhu, 2003; Ashley et al., 2006; Shabala and Cuin, 2008; Szczerba et al., 2009; Aleman et al., 2011; Shabala and Pottosin, 2014; Shabala et al., 2015; Coskun et al., 2016). Osmotically driven water fluxes resulting in cell volume changes are fundamental for cell elongation and essential for endogenous movement named circumnutation (CN) (Johnsson, 1979; Millet and Badot, 1996; Shabala and Newman, 1997; Shabala and Knowles, 2002; Shabala, 2003; Stolarz, 2009; Grefen et al., 2011; Kurenda et al., 2015). An endogenous $\mathrm{CN}$ can be modulated by multiple external stimuli e.g., light, wounding, touch, temperature, chemicals, and gravity as well as by organ morphology and biological clock (Buda et al., 2003; Hayashi et al., 2004; Charzewska and Zawadzki, 2006; Stolarz, 2009; Stolarz et al., 2010). CNs are an effect of highly coordinated and phase synchronized cell elongation and intercellular communication inside the motor/elongation zone of a growing organ. The membrane potential changes and ion fluxes are important elements of the CN mechanism (Millet and Badot, 1996; Stolarz, 2009; Kurenda et al., 2015). The ion content in the soil (nutrient solution), ion uptake, and ion content in the apoplast and symplast is therefore essential for transmembrane potential maintenance; it could change plant excitability and cell volume and growth and thus $\mathrm{CN}$. Growth inhibition in plants is a most frequently defined effect of environmental stress, including salt stress (Zhu, 2003; Foster and Miklavcic, 2015; Wu et al., 2015a). CNs are closely related to growth, and $\mathrm{CN}$ changes after many environmental stimuli have been described (Buda et al., 2003; Stolarz et al., 2008, 2015; Stolarz, 2009; Kurenda et al., 2015). An endogenous motor activity and electrical long-distance signaling in the form of CNs and APs have been well-characterized in $H$. annuus. $H$. annuus is an important agricultural crop grown for oil, fresh green mass, and as ornamental plants whose yield can be reduced by drought and the accompanying osmotic and salt stress. The sunflower is studied simultaneously as a crop with relatively high tolerance to drought and therefore osmotic and saline stress (Mukherjee et al., 2014; Ceccoli et al., 2015; Wu et al., 2015b; Singh and Bhatla, 2016). Investigations of the effect of the osmotic potential of the nutrient medium on the transmission of electrical signals and changes in endogenous motor activity of the sunflower may provide new information on the role of intercellular communication in plant adaptation to changing environmental conditions.

The aim of our study was to characterize the effect of osmotic and salt stress on growth, $\mathrm{CN}$ parameters, and appearance of APs. A different effect of salt stress than osmotic stress on $\mathrm{CN}$ and, hence, on the growth and appearance of APs was revealed. For the first time, spontaneous APs in seedlings growing in a hydroponic medium and enhancement of spontaneous excitation in sunflower seedlings by salinity were shown.

\section{MATERIALS AND METHODS}

\section{Experimental Plants} Sunflower Seedlings

Seeds of $H$. annuus L. (PNOS, Ozarów Maz., Poland) were germinated on wet filter paper in a thermostatted $\left(24 \pm 1^{\circ} \mathrm{C}\right)$ darkened chamber. After 4 days, seedlings with $4.5 \pm 0.5-\mathrm{cm}-$ long hypocotyls were cultivated hydroponically (10 plants per pot) in an aerated nutrient solution. The hydroponic culture was maintained for 3 days under constant illumination, 40 $\mu \mathrm{mol} \mathrm{m}{ }^{-2} \mathrm{~s}^{-1}$ white light (Power Star HQT-T400 W/D OSRAM $\mathrm{GmbH}$, Munich, Germany), at a temperature of $24 \pm 1^{\circ} \mathrm{C}$ and relative humidity $50-70 \%$. The seedlings were grown for 3 days in a control medium or were treated with different $\mathrm{KCl}, \mathrm{NaCl}$, and D-sorbitol concentrations and simultaneously filmed for $\mathrm{CN}$ measurements. In 7-day-old seedlings, the length of the seedling hypocotyl was measured and electrophysiological measurements of the seedlings were performed.

\section{Three Week-Old Sunflowers}

The studies were carried out on 3 week-old $H$. annuus L. plants (PNOS, Ożarów Maz. Poland) grown in a vegetation room in pots filled with garden soil. They were watered with tap water and no other treatment was applied. A 16:8 h light:dark (4:00 a.m.-8:00 p.m.) photoperiod was maintained. The intensity of white light in the PAR (Photosynthetic Active Radiation) range (Power Star 
HQT-T400 W/DOSRAM GmbH, Munich, Germany) at the level of plant leaves was $\sim 70 \mu \mathrm{mol} \mathrm{m}^{-2} \mathrm{~s}^{-1}$. The vegetation room was air-conditioned; the temperature was $24 \pm 1^{\circ} \mathrm{C}$ and humidity $50-70 \%$. Approximately $20-30 \mathrm{~cm}$ high plants with one or two pairs of developed leaves were taken for the experiments. The 3week old plants were transferred to a Faraday cage at $\sim 12: 00$ and electrodes were inserted. Distilled water, D-sorbitol, $\mathrm{KCl}$, or $\mathrm{NaCl}$ were injected between 6:00 p.m.-7:00 p.m.

\section{Time-Lapse Method and CN Measurements}

For CN measurements, time-lapse photography recordings were made from 09:00 a.m. on the fourth day to 09:00 a.m. on the seventh day of seedling growth. A monochromatic camera (Mintron MTV-1368CD, Mintron Enterprise Co. Ltd, Taipei, Taiwan) was used to record the circumnutation trajectory of the hypocotyls apex. The plants were filmed from the top. Time-lapse images were recorded one frame per $5 \mathrm{~min}$ by Gotcha! Multicam software (Prescient System Inc., West Chester, PA, USA). The system was calibrated in a millimeter scale. The time-lapse images were digitized using Circumnutation Tracker (Stolarz et al., 2014) and Microsoft Excel programs. Experimental points (coordinates $x, y$ of the stem apex on the horizontal plane) were determined at 5-min intervals. In the geographic direction plane, the single circumnutation cycle is determined by two subsequent maximum northward bends of the organ (Stolarz et al., 2014). Supplementary Video $\mathrm{S} 1$ shows subsequent $\mathrm{CN}$ cycles of sunflower seedlings. The distance covered by the hypocotyls apex during one $\mathrm{CN}$ cycle was used to calculate the $\mathrm{CN}$ rate. $\mathrm{CN}$ intensity was the rate of $\mathrm{CN}$ divided by the length of the hypocotyls. The $\mathrm{CN}$ period was the time required for the hypocotyls apex to trace a single $\mathrm{CN}$ cycle (time between two subsequent maximum northward bends of the organ) (Stolarz et al., 2014).

\section{Electrophysiological Measurements-Extracellular Method}

The electrical measurements were carried out in a Faraday cage on 7- to 8-day-old seedlings or 3-week-old sunflowers. The changes in the electrical potential were measured with two or four extracellular $\mathrm{Ag} / \mathrm{AgCl}$ electrodes (a silver wire, $0.2 \mathrm{~mm}$ diameter, World Precision Instruments, Sarasota, FL, USA) inserted across the sunflower hypocotyl or stem and then interfaced with a multi-channel data acquisition system composed of a differential amplifier (ME-4600 Meilhaus, Germany) and RealView software (Abacom, Germany) (Supplementary Figure S1). During the preparation of the $\mathrm{Ag} / \mathrm{AgCl}$ electrodes, the silver wire was electrolytically coated with silver chloride. The electrical potential was recorded from tissues adjacent to the electrode, i.e., vascular bundles, parenchyma, and epidermis (Dziubinska et al., 2001). The reference electrode $(\mathrm{Ag} / \mathrm{AgCl})$ was placed in the hydroponic medium or soil. The frequency of sample recording was $1 \mathrm{~Hz}$. For registration of SAPs (spontaneous action potentials), seedlings grew in the Faraday cage in a hydroponic solution for 3 days. Glutamate (Glu) injection was applied between 8:00 a.m.-2:00 p.m. in 7-8-day-old seedlings growing in different nutrient solutions for 3 days.

\section{Chemicals}

\section{Hydroponic Culture}

The nutrient solution contained $4 \mathrm{mM} \mathrm{Ca}\left(\mathrm{NO}_{3}\right)_{2} \times 4 \mathrm{H}_{2} \mathrm{O}$, $5 \mathrm{mM} \quad \mathrm{KNO}_{3}, 1 \mathrm{mM} \mathrm{NH}_{4} \mathrm{H}_{2} \mathrm{PO}_{4}, 2 \mathrm{mM} \mathrm{MgSO}_{4} \times 7 \mathrm{H}_{2} \mathrm{O}$;

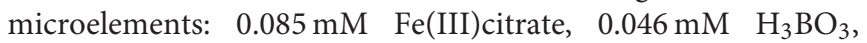
$0.0009 \mathrm{mM} \mathrm{MnCl} 2 \times 4 \mathrm{H}_{2} \mathrm{O}, 0.0003 \mathrm{mM} \mathrm{CuSO} 4 \times 5 \mathrm{H}_{2} \mathrm{O}$, $0.0008 \mathrm{mM} \mathrm{ZnSO} \mathrm{Zn}_{4} \times 7 \mathrm{H}_{2} \mathrm{O}, 0.0001 \mathrm{mM} \mathrm{H} \mathrm{H}_{2} \mathrm{MoO}_{4} \times 2 \mathrm{H}_{2} \mathrm{O}$; (pH 6.0); the osmotic potential was $23 \mathrm{mOsm}$. Additionally, $80 \mathrm{mM}$ (160 mOsm), $120 \mathrm{mM} \mathrm{(240} \mathrm{mOsm),} \mathrm{and} 160 \mathrm{mM}$ (300 mOsm) potassium chloride ( $\mathrm{POCH}$, Poland) and sodium chloride (POCH, Poland) in the nutrient solution was used as a hyperosmotic salt stress. Hyperosmotic stress was adjusted by $160 \mathrm{mM}$ (160 mOsm) D-sorbitol (POCH, Poland). The osmotic potential was measured with a cryoscopic osmometer (Osmomat 030, Gonotec GmbH, Berlin, Germany).

\section{Injection}

Twenty microliters of a $50 \mathrm{mM}$ Glu solution (L-glutamic acid, ICN Biomedicals, Germany, $\mathrm{pH}$ adjusted to 7 by Tris/Mes buffer), distilled water, $250 \mathrm{mM} \mathrm{KCl}(500 \mathrm{mOsm})$ ( $\mathrm{POCH}$, Poland), $250 \mathrm{mM} \mathrm{NaCl}$ (500 mOsm) (POCH, Poland), and $500 \mathrm{mM}$ D-sorbitol (500 mOsm) (POCH, Poland) were injected with a syringe into the seedlings at the base of the hypocotyls (Glu), $1 \mathrm{~cm}$ above the root collar, or at the base of the stem in the 3-week old plants. The injection of the solution lasted a few seconds. The injury of the sunflower hypocotyls or stem with a syringe needle induced either only one AP or none (Stolarz et al., 2010).

\section{Statistical Analysis}

The data were analyzed using Statistica ver. 12 software (StatSoft, Inc., 2014). The data set was first tested for normality using Shapiro-Wilk test and homogeneity of variance by Levene's test. The non-parametric Kruskal-Wallis ANOVA and nonparametric Mann-Whitney $U$-test for pairwise analysis were used when the data had non-normal distribution or unequal variance. The one-way ANOVA and post-hoc Tukey test for pairwise analysis were used when the data had normal distribution and equal variance. The level of statistical significance for all tests was set at $p<0.05$.

\section{RESULTS}

The sunflower seedlings treated with hypoosmotic (distilled water) and hyperosmotic (D-sorbitol, $\mathrm{KCl}$ and $\mathrm{NaCl}$ ) nutrient solutions in the hydroponic culture were characterized by decreased growth and changes in the $\mathrm{CN}$ parameters. Spontaneous excitation was also modified by the osmotic potential of the nutrient solution. Additionally, localized stimuli-the injection of the glutamate solution at the base of hypocotyls or the hypo- or hyperosmotic solution at the base of the stem induced different numbers of APs dependent on the kind of the injected solution and the osmotic potential of the nutrient. 


\section{Effect of Osmotic and Salt Stress on the Growth and CN Intensity in Sunflower Seedlings}

The sunflower seedlings growing in the control nutrient solution (23 mOsm) had $10 \pm 0.6 \mathrm{~cm}(n=20)$ long hypocotyls. Both the hypoosmotic and hyperosmotic nutrient solutions reduced the hypocotyl length in a statistically significant way by $\sim 10-30 \%$ (Figure 1A, Supplementary Figure S2). Simultaneously, the $\mathrm{CN}$ parameters changed differently in the osmotic and salt stress conditions. Sunflower seedlings growing in distilled water (0 mOsm) had significantly shortened hypocotyls and drastically reduced $\mathrm{CN}$ intensity in relation to those growing in the control nutrient solution (Figures 1A,B). Similarly, the high osmotic potential (160 mOsm) evoked by D-sorbitol significantly shortened the hypocotyl length and drastically reduced $\mathrm{CN}$ intensity (Figures 1A,B). In turn, the increase in the osmotic potential to $160-300 \mathrm{mOsm}$ induced by salt $(\mathrm{KCl}$ or $\mathrm{NaCl})$ did not influence the $\mathrm{CN}$ intensity although the hypocotyl length was significantly reduced (Figures 1A,B). Sunflower seedlings with similar hypocotyl length exhibited completely different $\mathrm{CN}$ intensity in osmotic and salt stress. The CNs were strongly inhibited in distilled water and $160 \mathrm{mM} \mathrm{D}$-sorbitol (160 mOsm) but were vigorous (as in the control seedlings) in the salt stress inducing solutions (160-300 mOsm $\mathrm{KCl}$ and $\mathrm{NaCl}$ ). The osmotically induced growth inhibition was accompanied by a decrease in the $\mathrm{CN}$ intensity but the salt-induced growth inhibition had little effect on the $\mathrm{CN}$ intensity.

\section{Effect of Osmotic and Salt Stress on the CN Period in Sunflower Seedlings}

In the sunflower seedlings, the mean $\mathrm{CN}$ period in the control solution was $174 \pm 6 \mathrm{~min}(n=20$, Figure $1 \mathrm{C})$. The $\mathrm{CN}$ period was lengthened in a statistically significant way in seedlings growing in distilled water $(0 \mathrm{mOsm})$ to $245 \pm 19 \mathrm{~min}(n=10)$. The CN period was longer by $70 \mathrm{~min}$. Simultaneously, the $\mathrm{CN}$ period in seedlings growing in the $\mathrm{D}$-sorbitol, $\mathrm{KCl}$, and $\mathrm{NaCl}$ solutions (160-300 $\mathrm{mOsm}$ ) was the same as in the control conditions. In $120 \mathrm{mM} \mathrm{NaCl}$ and $160 \mathrm{mM} \mathrm{KCl}$, it was significantly longer but only by $\sim 15 \mathrm{~min}$. The $\mathrm{CN}$ period was the same as in the control in the mild salt stress and even in the strong stress $(160 \mathrm{mM} \mathrm{NaCl})$. The hypocotyls of the same length had a completely different $\mathrm{CN}$ period in the osmotic and salt solution, which proves the absence of a strict connection between the $\mathrm{CN}$ and hypocotyl growth.

Given the above results, it can be assumed that only the osmotic stress disturbs growth and $\mathrm{CN}$ (intensity and period); in turn, the salt stress disturbs the growth mechanism only and does not influence the $\mathrm{CN}$ mechanism. This shows that there is a salt stress-resistant ultradian pacemaker in the sunflower and confirms that the presence of ions in the nutrient solution is basic for the $\mathrm{CN}$ mechanism.

$\mathrm{K}^{+}, \mathrm{Cl}^{-}$, and $\mathrm{Na}^{+}$are also essential for membrane potential maintenance and excitability of organisms; therefore, we expect that the sunflower seedlings growing under different $\mathrm{K}^{+}, \mathrm{Cl}^{-}$, and $\mathrm{Na}^{+}$contents in the nutrient solution could have a different excitability.

\section{Spontaneous Action Potentials in Sunflower Seedlings}

The number, velocity, and direction of propagation of SAPs were determined in salt and osmotically stressed sunflower seedlings (Figure 2, Table 1). An example of SAPs in sunflower seedlings is shown in Figure 2 and Supplementary Video S2. In the control conditions, $3 \pm 1$ SAPs $24 \mathrm{~h}^{-1}$ plant $^{-1}(n=12)$ were registered, which propagated mainly basipetally (75\%) with a mean velocity $14 \pm 1 \mathrm{~cm} \mathrm{~min}{ }^{-1}$. This was similar in the strong salt stress conditions ( $300 \mathrm{mOsm} \mathrm{KCl}$ and $\mathrm{NaCl}$ ) (Table 1). In the seedlings growing in distilled water and in D-sorbitol (160 mOsm), SAPs were completely silenced. The number of SAPs significantly increased in mild $\mathrm{KCl}$ stress where the number of SAPs increased two and three times to 10 SAPs $24 \mathrm{~h}^{-1}$ plant $^{-1}$, compared to the control and 300 mOsm salt solution. Similarly, in mild $\mathrm{NaCl}$ stress, the SAP number slightly increased to 7 SAPs $24 \mathrm{~h}^{-1}$ plant $^{-1}$ and SAP propagation velocity significantly increased to $20 \pm 1 \mathrm{~cm} \mathrm{~min}^{-1}$ in those seedlings. The percentage of basipetally and acropetally propagating SAPs remained similar in all conditions (Table 1). The complete lack of SAPs in distilled water and the 160 mOsm D-sorbitol solution as well as the significantly increased number of SAPs and their propagation velocity in mild salt stress showed that the $\mathrm{K}^{+}, \mathrm{Cl}^{-}$, and $\mathrm{Na}^{+}$concentration in the nutrient solution modulated spontaneous excitability. The silencing of SAPs and the reduced vigor of CNs indicates that SAPs and CNs were repressed by the lack of ions or ion uptake disturbance in distilled water and the hyperosmotic D-sorbitol solution. Mild and strong salt stress nutrient conditions maintain CNs and maintain or even enhance SAPs; thus, these results show an essential role of $\mathrm{K}^{+}, \mathrm{Cl}^{-}$, and $\mathrm{Na}^{+}$ions in both phenomena.

\section{Glu-Induced Series of APs in the Hypocotyls of Sunflower Seedlings}

Besides SAPs, Glu-induced series of APs in osmotically and salt-stressed seedlings were studied. The series of APs evoked by injection of the $50 \mathrm{mM}$ Glu solution in the control plants consisted of $10 \pm 1$ APs $(n=10)$ (Figure 2D, Table 2). Similar series were obtained in mild stress in the D-sorbitol, $\mathrm{KCl}$ and $\mathrm{NaCl}(160 \mathrm{mOsm})$ treated seedlings; however, in strong $\mathrm{KCl}$ and $\mathrm{NaCl}(320 \mathrm{mOsm})$ stress, the series were significantly inhibited to 2-3 APs in a series (Figure 2D, Table 2). Seedlings growing in distilled water exhibited reduced growth, CNs (Figures 1A,B), and Glu-induced series of APs (only 30\% of the seedlings were excitable, Table 2), compared to the control plants. Seedlings growing in D-sorbitol (160 mOsm) had shorter hypocotyls and reduced $\mathrm{CN}$ but generated Gluinduced series, likewise the control and mild stress-treated plants, which had shorter hypocotyls and unchanged vigor of CN. Additionally, sunflower seedlings treated with strong salt stress $(300 \mathrm{mOsm})$ had a reduced hypocotyl length and unchanged $\mathrm{CN}$, but the Glu-induced series of APs were strongly inhibited.

The spontaneous and glutamate-induced excitability changes in seedlings growing in the osmotic and salt stress conditions 


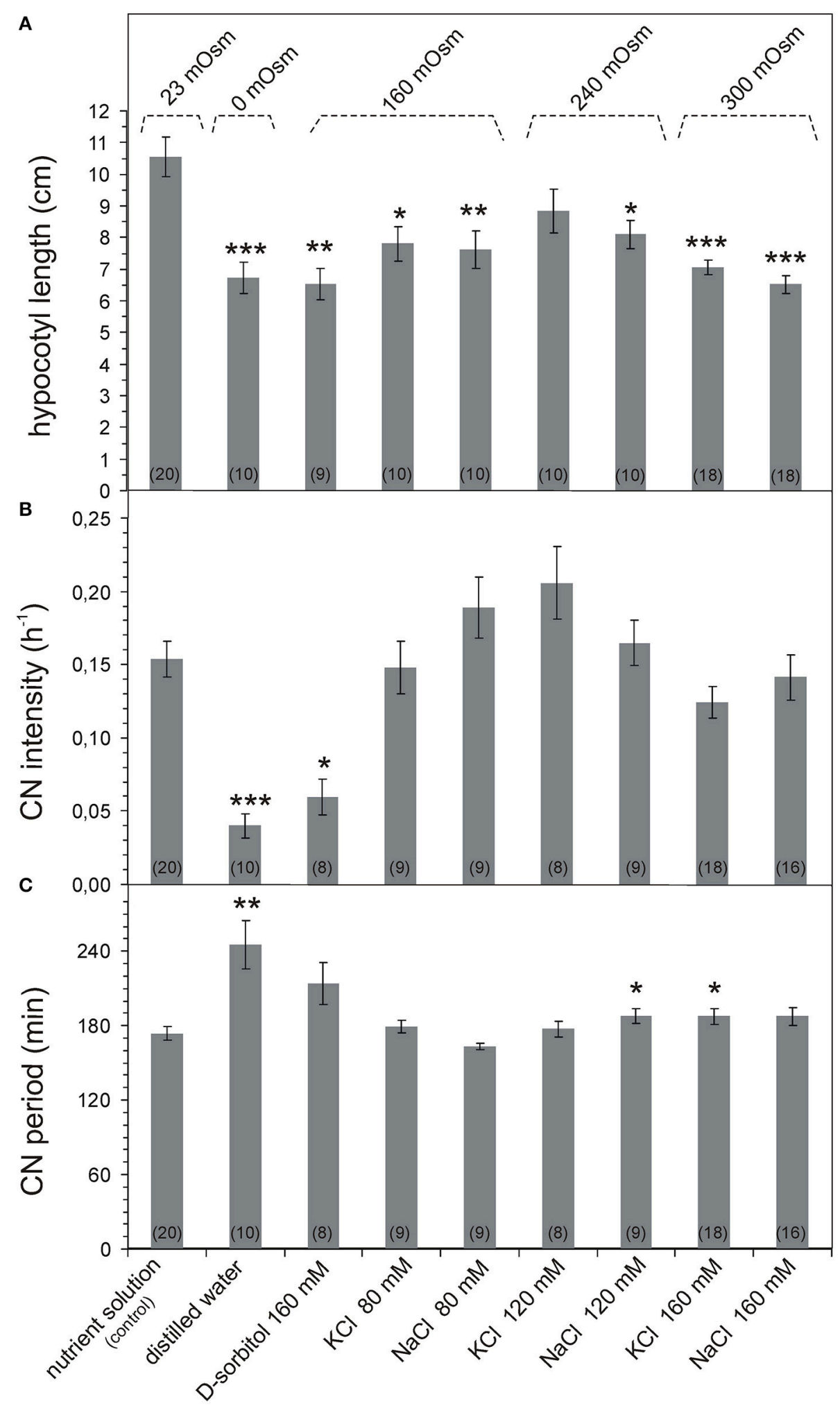

FIGURE 1 | Parameters of growth and CN of Helianthus annuus seedlings under osmotic and salt stresses. Bars represent mean \pm SE. The number of plants is indicated in parentheses. The data were tested for normality distribution using the Shapiro-Wilk test. The the non-parametric Mann-Whitney $U$-test for pairwise analysis $(\mathbf{A}, \mathbf{C})$ and Tukey test $\mathbf{( B )}$ were used to assess the statistical difference between the control plants and each sunflower group growing in different nutrients; $p$-value ranges are marked by asterisks: ${ }^{\star \star \star} p<0.001,{ }^{\star \star} p<0.01,{ }^{\star} p<0.05$. (A) Changes in hypocotyl length, data normally distributed, unequal variance 


\section{FIGURE 1 | continued}

(Levene's test $p=0.000109$ ), Kruskal-Wallis ANOVA (Chi square $=27.39 \mathrm{df}=8 p=0.0006)$. (B) Changes in hypocotyl CN intensity. The distance covered by the hypocotyl apex during one cycle was used to calculate the $\mathrm{CN}$ rate. $\mathrm{CN}$ intensity was the rate of $\mathrm{CN}$ divided by hypocotyl length. Data normally distributed, equal variance Levene's test $(p=0.30$ ), one-way ANOVA ( $S S=0.2149 \mathrm{df}=8 \mathrm{~F}=10.015 p=0.0000)$. (C) Changes in hypocotyl CN period. The CN period was the time required by the hypocotyl apex to trace a single $\mathrm{CN}$ cycle (time between two subsequent maximum northward bends of the hypocotyl). Data normally distributed, unequal variance (Levene's test $p=0.000053$ ), Kruskal-Wallis ANOVA (Chi square $=24.55 \mathrm{df}=8 p=0.0018$ ).
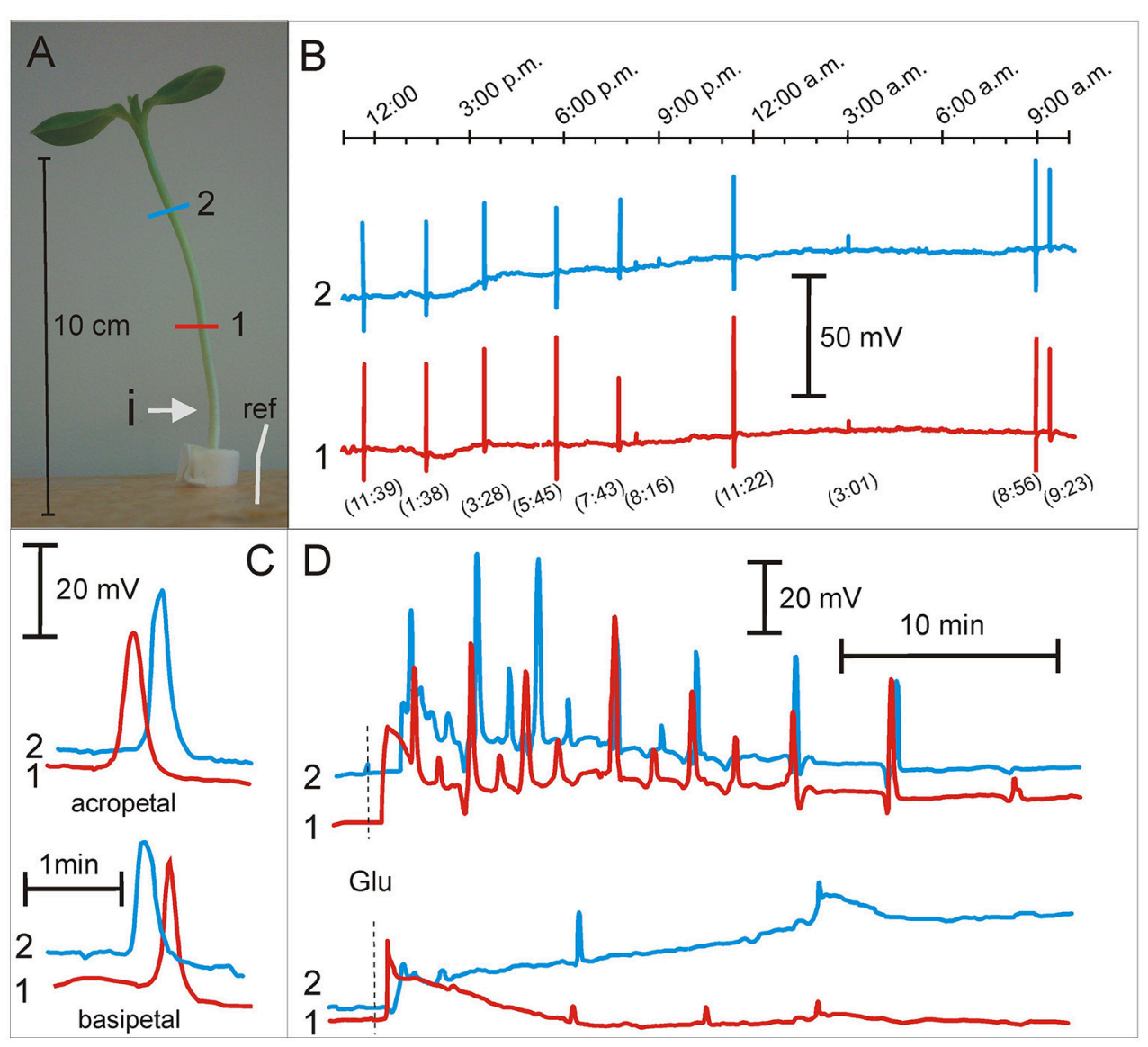

FIGURE 2 | Spontaneous action potentials and glutamate induced series of action potentials in Helianthus annuus seedlings under osmotic and salt stresses. (A) Helianthus annuus seedlings, electrode arrangement (1,2, ref-reference electrode) and site of glutamate injection (i). (B) Example of recordings of spontaneous action potentials during 1 day (also shown in Supplementary Video S2). In the parentheses, the time of SAP appearing. (C) Example of recordings of acropetally and basipetally propagating spontaneous action potentials. (D) Example of recordings of action potential series after glutamate (Glu) injection into the hypocotyl base of seedlings growing under $80 \mathrm{mM} \mathrm{KCl} \mathrm{(upper)} \mathrm{as} \mathrm{well} \mathrm{as} 160 \mathrm{mM} \mathrm{NaCl}$ nutrient solutions (lower). Data details are presented in Tables 1, 2.

encouraged us to check the APs appearing after injection of the hypoosmotic and hyperosmotic solution in 3-week old sunflower plants.

\section{Osmotically and Salt-Induced Series of APs in the Stem of 3-Week Old Sunflowers}

Injection of distilled water or 500 mOsm solutions (D-sorbitol, $\mathrm{KCl}$ ) into the sunflower stem evoked series of APs presented in Figure 3. The parameters of sunflower excitation after injection of the osmotic and salt solutions are presented in Table 3. Distilled water, D-sorbitol, and $\mathrm{KCl}$ solutions evoked series of 3 to 24 APs in $70-100 \%$ of treated plants. APs propagated mainly acropetally from the site of injection toward the stem apex, at an $\sim 15 \mathrm{~cm}$ long distance. The injection of the $\mathrm{NaCl} 250 \mathrm{mM}$ solution did not evoke APs (Supplementary Figure S3). These results show that a series of long-distance propagating $(\sim 15 \mathrm{~cm})$ APs in the sunflower stem can be induced by distilled water, D-sorbitol and $\mathrm{KCl}$ but not by $\mathrm{NaCl}$.

\section{DISCUSSION}

Closure of the trap leaf in Dionaea and leaf folding in Mimosa after touching are commonly known, easily observable examples of plant responses to environmental stimuli, in which 
TABLE 1 | Parameters of spontaneous excitation in Helianthus annuus seedlings under osmotic and salt stresses.

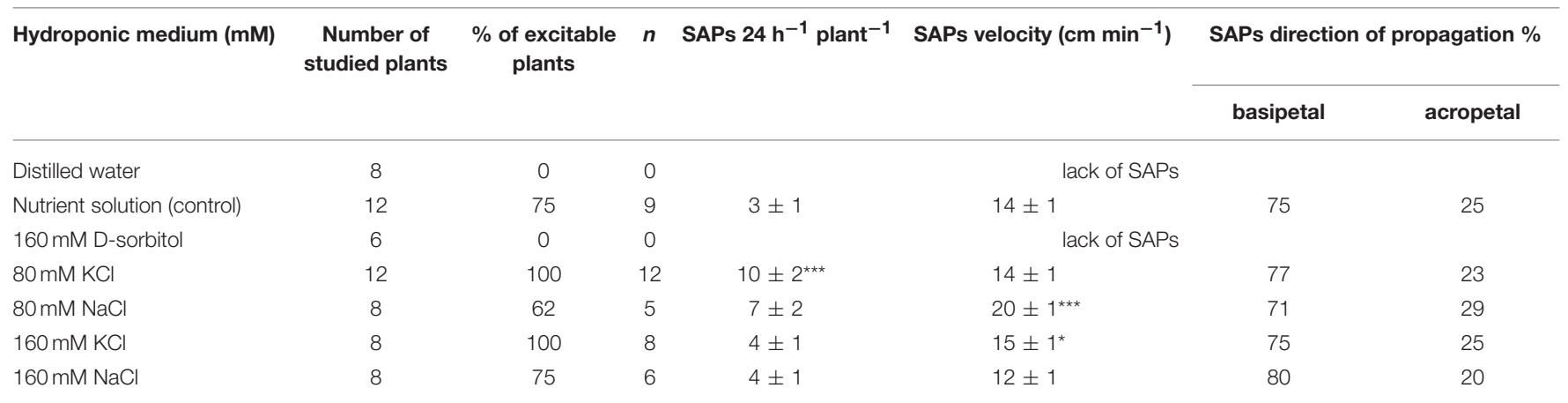

Propagation velocity of APs was calculated by taking the distance between the electrodes and dividing it by the time necessary for AP to move between the electrodes. Basipetal SAPS are SAPs propagating downwards the stem; acropetal SAPs are SAPs propagating upwards the stem; $n$-number of seedlings with SAPS.

SAPs $24 \mathrm{~h}^{-1}$ plant ${ }^{-1}$ : data non-normally distributed, unequal variance (Levene's test $p=0.000022$ ), Kruskal-Wallis ANOVA (Chi square $=10.31 \mathrm{df}=4 \mathrm{p}=0.0354$ ). SAP velocity: data non-normally distributed, unequal variance (Levene's test $p=0.000022$ ), Kruskal-Wallis ANOVA (Chi square $=33.66 \mathrm{df}=4 p=0.0000$ ). Mann-Whitney U-test was used to assess the statistical difference between the control plants and each sunflower group growing in different nutrients. $p$-value ranges are marked by asterisks: ${ }^{* \star} p<0.001,{ }^{*} p<0.05$.

TABLE 2 | Parameters of glutamate induced series of action potentials in Helianthus annuus seedlings growing under osmotic and salt stresses.

\begin{tabular}{|c|c|c|c|c|}
\hline $\begin{array}{l}\text { Hydroponic } \\
\text { medium (mM) }\end{array}$ & $\begin{array}{l}\text { Number } \\
\text { of studied } \\
\text { plants }\end{array}$ & $\begin{array}{c}\% \text { of excitable } \\
\text { plants }\end{array}$ & $n$ & APs series \\
\hline
\end{tabular}

\begin{tabular}{|c|c|c|c|c|c|}
\hline & & & & & \\
\hline & & & & $\begin{array}{c}\text { APs } \\
\text { number }\end{array}$ & $\begin{array}{l}\text { Series duration } \\
\text { (min) }\end{array}$ \\
\hline Distilled water & 7 & 29 & 2 & $5 \pm 2$ & $13 \pm 2$ \\
\hline $\begin{array}{l}\text { Nutrient } \\
\text { solution } \\
\text { (control) }\end{array}$ & 10 & 100 & 10 & $10 \pm 1$ & $20 \pm 5$ \\
\hline $\begin{array}{l}160 \mathrm{mM} \\
\text { D-sorbitol }\end{array}$ & 14 & 100 & 14 & $10 \pm 1$ & $22 \pm 5$ \\
\hline $80 \mathrm{mM} \mathrm{KCl}$ & 16 & 100 & 16 & $11 \pm 1$ & $35 \pm 3^{\star}$ \\
\hline $80 \mathrm{mM} \mathrm{NaCl}$ & 8 & 50 & 4 & $7 \pm 1$ & $16 \pm 5$ \\
\hline $160 \mathrm{mM} \mathrm{KCl}$ & 12 & 58 & 7 & $2.4 \pm 0.2^{\star \star \star}$ & $9 \pm 2$ \\
\hline $160 \mathrm{mM} \mathrm{NaCl}$ & 13 & 69 & 9 & $2.8 \pm 0.3^{\star \star \star}$ & $33 \pm 15$ \\
\hline
\end{tabular}

The duration of the series is the time between the first and the last AP in the series. $n-$ number of excitable plants. AP number: data non-normally distributed, unequal variance (Levene's test $p=0.0020$ ), Kruskal-Wallis ANOVA (Chi square $=27.22 d f=6 p=$ 0.0001). Series duration: data non-normally distributed, unequal variance (Levene's test $p$ $=0.0421$ ), Kruskal-Wallis ANOVA (Chi square $=13.57 d f=6 p=0.0421$ ). Mann-Whitney $U$-test was used to assess the statistical difference between the control plants and each sunflower group growing in different nutrients. $p$-value ranges are marked by asterisks: ${ }^{\star * *} p<0.001,{ }^{*} p<0.05$.

the universal biological signal AP is involved. Thanks to the recent well-developed time-lapse photography method, slow endogenous organ motion can be visualized and investigated under stimuli and environmental changes (Buda et al., 2003; Stolarz et al., 2003, 2014; Kurenda et al., 2015). Long lasting extracellular electrical measurements can show also plant excitability in a wide time span of even a few days (Zawadzki et al., 1995; Favre et al., 1999; Macedo et al., 2015). For better understanding of the role of APs as physiological signals in plants, SAPs and Glu-induced excitation was studied in osmotically and salt-stressed sunflower seedlings in relation to hypocotyl growth and $\mathrm{CN}$.

\section{Hypocotyl Elongation, But Not CN Intensity, was Decreased by Salinity Stress}

The problem of CN dependence on growth has been considered many times (Spurny, 1975; Johnsson, 1979, 1997; Millet and Badot, 1996; Stolarz et al., 2008). In general, CNs are dependent on growth, but in some environmental conditions, for example under lithium, red light, or ethylene treatment, growth and CN uncoupling was observed (Spurny, 1968; Zachariassen and Johnsson, 1988; Millet and Badot, 1996; Yoshihara and Iino, 2005; Binder et al., 2006; Stolarz et al., 2008, 2015). This study has shown that the osmotic and salt stress treatments distinguish between growth and $\mathrm{CN}$ behavior (Figures 1A,B). Significant inhibition of elongation of hypocotyls was observed when distilled water, $\mathrm{D}$-sorbitol, $\mathrm{KCl}$, and $\mathrm{NaCl}$ were applied (Figure 1A). The $\mathrm{CN}$ intensity decreased significantly only in seedlings growing in distilled water and D-sorbitol (Figure 1B). Seedlings with a similar hypocotyl length had different CN intensity in osmotic and salt stress. These results showed that the mechanism of elongation is influenced differently than the mechanism of $\mathrm{CN}$. The concentration of $80-160 \mathrm{mM} \mathrm{K}^{+}, \mathrm{Na}^{+}$, and $\mathrm{Cl}^{-}$decreased growth but did not affect the $\mathrm{CN}$ intensity. The absence of ions or ion uptake disturbance in distilled water or D-sorbitol inhibited growth and $\mathrm{CN}$.

Some other studies showed the different physiological effect of the "osmotic" and "ionic" component of salt stress. The "osmotic" and "ionic" component of salt stress differently modulated net ion fluxes in leaf mesophyll of Vicia faba (Shabala, 2000). Osmotic stress in barley regulated expression of a different set of genes than salt stress (Ueda et al., 2004). The effect of osmotic stress was also shown in Beta vulgaris when D-sorbitol-induced osmotic stress strongly reduced its growth and led to a significant decrease in shoot osmotic potential, water content, and $\mathrm{K}^{+}$concentrations ( $\mathrm{Wu}$ et al., 2015a).

\section{Stable CN Period in Salt Stress}

Circumnutation, a rhythmic phenomenon can be considered as a "cue" internal ultradian oscillator (Millet and Badot, 1996; 


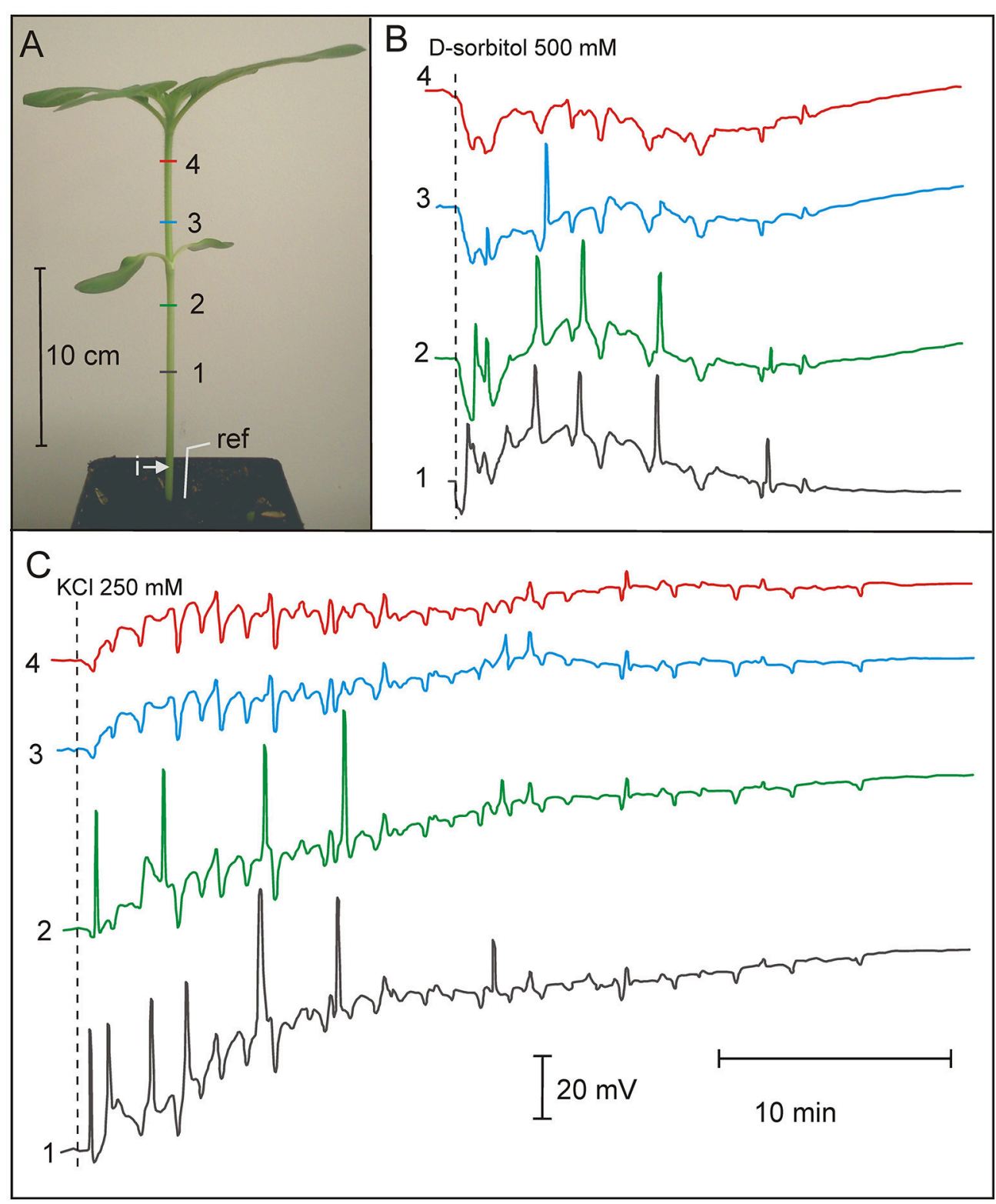

FIGURE 3 | Osmotically and potassium chloride-induced series of action potentials in 3-week old Helianthus annuus. (A) Helianthus annuus plants, electrode arrangement (1, 2, 3, 4, ref-reference electrode) and site of solution injection (i). (B) Example of recordings of action potential series after D-sorbitol 500 mOsm $(500 \mathrm{mM})$ injection into the stem base. (C) Example of recordings of action potential series after $\mathrm{KCl} 500 \mathrm{mOsm}(250 \mathrm{mM})$ injection into the stem base. Data details are presented in Table 3 .

Shabala, 2003; Lloyd, 2006). The CN period and it shortening or lengthening in various environmental conditions is important in a study of the ultradian pacemaker mechanism (Johnsson, 1979, 1997; Zachariassen and Johnsson, 1988; Stolarz, 2009; Hinrichsen et al., 2012). In this study, a stable period, despite the growth reduction, was shown (Figures 1A,C). The period of $\mathrm{CNs}$ in the mild and strong salt stress (163-188 min) was close to the $\mathrm{CN}$ period of the control plants $(174 \mathrm{~min})$. The CN period was lengthened significantly only in distilled water $(245 \mathrm{~min})$. This confirms a strong resistance of the $\mathrm{CN}$ period to osmotic and salt stress (Erdei et al., 1998). The independence of the $\mathrm{CN}$ period of the growth of hypocotyls confirmed some degree of independence between growth and $\mathrm{CN}$ behavior, as in the case of lithium treatment (Stolarz et al., 2015).

The results presented above confirmed again the autonomy of $\mathrm{CN}$ behavior in relation to elongation and special physiological and ecological functions of CN being not merely a strict result of growth (Darwin and Darwin, 1880; Inoue et al., 1999; Larson, 2000; Kosuge et al., 2013; Migliaccio et al., 2013). 
TABLE 3 | Parameters of osmotic and salt-induced series of action potentials in 3-week old Helianthus annuus.

\begin{tabular}{|c|c|c|c|c|c|}
\hline \multirow{2}{*}{$\begin{array}{l}\text { Solution } \\
\text { injected }\end{array}$} & \multirow{2}{*}{$\begin{array}{c}\text { Number of } \\
\text { treated } \\
\text { plants }\end{array}$} & \multirow{2}{*}{$\begin{array}{c}\% \text { of } \\
\text { excitable } \\
\text { plants }\end{array}$} & \multirow[t]{2}{*}{$n$} & \multicolumn{2}{|c|}{ Series of AP } \\
\hline & & & & $\begin{array}{c}\text { APs } \\
\text { number }\end{array}$ & $\begin{array}{c}\text { Series duration } \\
\text { (min) }\end{array}$ \\
\hline $\begin{array}{l}\text { Distilled } \\
\text { water } \\
0 \text { mOsm }\end{array}$ & 9 & 70 & 6 & $6 \pm 1^{a}$ & $11 \pm 2^{\mathrm{a}}$ \\
\hline $\begin{array}{l}\text { D-sorbitol } \\
500 \mathrm{mM} \\
500 \mathrm{mOsm}\end{array}$ & 8 & 100 & 8 & $8 \pm 1^{a}$ & $13 \pm 1^{a}$ \\
\hline $\begin{array}{l}\mathrm{KCl} \\
250 \mathrm{mM} \\
500 \mathrm{mOsm}\end{array}$ & 7 & 100 & 7 & $17 \pm 1^{b}$ & $27 \pm 2^{b}$ \\
\hline $\begin{array}{l}\mathrm{NaCl} \\
250 \mathrm{mM} \\
500 \mathrm{mOsm}\end{array}$ & 10 & 0 & 0 & lack & f series of APs \\
\hline
\end{tabular}

The duration of the series is the time between the first and the last $A P$ in the series. $n-$ number of excitable plants. AP number: data normally distributed, unequal variance (Levene's test $p=0.0025$ ), Kruskal-Wallis ANOVA (Chi square $=13.48 d f=2 p=0.0012$ ). Series duration: data normally distributed, unequal variance (Levene's test $p=0.0017$ ), Kruskal-Wallis ANOVA (Chi square $=17.29 d f=2 p=0.0002$ ). Mann-Whitney U-test was used to assess the statistical differences in one parameter between the groups; different letters denote statistical difference.

\section{Mild Salt Stress Enhances Spontaneous Action Potentials in Sunflower Seedlings}

In plants, beside the stimulus-induced APs (electrical and mechanical stimuli, light, temperature, chemicals), there are SAPs. The SAPs appear in the absence of external stimuli and their endogenous source is unknown. SAPs were previously observed in 3-week old Helianthus and Lycopersicum plants growing in pots with standard soil (Zawadzki et al., 1995; Macedo et al., 2015). In this study, we have shown for the first time SAPs in sunflower seedlings growing in a hydroponic medium (Figure 2, Supplementary Video S2). This offered a new opportunity to modify the nutrient composition and investigate SAPs in plants in a specified nutrient environment.

In this work, we have described the number of SAPs per $24 \mathrm{~h}^{-1}$ plant $^{-1}$ as a parameter of endogenous "firing," which we have shown to be able to appear in control conditions (no external stimuli) but were modulated by osmotic and ionic stress. In the controlled nutrient conditions, the sunflower seedlings generated $3 \pm 1$ SAPs $24 \mathrm{~h}^{-1}$ plant $^{-1}(n=12)$. This number of SAPs persisted even under strong salt stress but completely disappeared in the distilled water and D-sorbitol $(160 \mathrm{mM}, 160$ mOsm) treatment (Table $\mathbf{1}$ ). The number of SAPs increased significantly to $10 \pm 2$ SAPs $24 \mathrm{~h}^{-1}$ plant $^{-1}(n=12)$ in $80 \mathrm{mM}$ $\mathrm{KCl}(160 \mathrm{mOsm})$. This showed that the "ionic" but not "osmotic" component of salt stress increased the number of SAPs. The number of SAPs $24 \mathrm{~h}^{-1}$ plant $^{-1}$ differed in the different nutrient conditions. These results demonstrate that sunflower seedlings are capable of generating many APs, and in a sufficiently long time, we can consider this as a specific frequency code of APs. In slowly moving hypocotyls of sunflower seedlings, this approach is justified. Slow motion of hypocotyls is accompanied by low frequency electrical signals (from 1 to 45 of APs during $24 \mathrm{~h}$ per seedling). In such a long time span, there are various numbers of SAPs and this amount can be modulated by the nutrient environment; therefore, there is endogenous electrical activity with very low frequency coding in sunflower seedlings. SAPs are known to propagate acropetally and basipetally. Basipetally propagating SAPs dominated in all nutrient solutions. They appeared in the upper part of the seedlings and propagated downwardly. This showed that the upper part of the seedlings generated more SAPs than the lower part. The amplitudes were in the range of $5-60 \mathrm{mV}$ and the rate of propagation was $12-20 \mathrm{~cm} \mathrm{~min}^{-1}$. In evoked APs, the amplitude is relatively constant $(50-60 \mathrm{mV})$. Significantly lower amplitudes of some SAPs indicate that the excitation is transmitted along individual phloem vessels but not along the transmitting system as in the case of evoked APs. Seedlings growing in the mild $\mathrm{NaCl}$ stress exhibited significantly higher SAP propagation velocity than the control plants. The amplitude and velocity of propagation was similar to that in 3-week old Helianthus and Lycopersicum plants growing in pots with standard soil (Zawadzki et al., 1995; Macedo et al., 2015).

In the research of changes in excitability in sunflowers, we used $\mathrm{KCl}$ and $\mathrm{NaCl}$. A treatment with the $\mathrm{KCl}$ solution was applied because $\mathrm{K}^{+}$is an important component of the AP mechanism and transmembrane potential maintenance (Trebacz et al., 1989, 1994; Shabala, 2003; Johansson et al., 2006; Shabala and Cuin, 2008; Aleman et al., 2011; Dreyer and Uozumi, 2011; Shabala and Pottosin, 2014; Salvador-Recatala, 2016). In turn, $\mathrm{NaCl}$ was used because it is the most commonly occurring salt in the environmental salt stress (Munns and Tester, 2008; Maathuis, 2014; Foster and Miklavcic, 2015). The mechanism of the action of environmental salt $(\mathrm{NaCl})$ stress on plants also includes $\mathrm{K}^{+}$ homeostasis disturbance (Shabala and Cuin, 2008; Foster and Miklavcic, 2015). The effect of $\mathrm{KCl}$ and $\mathrm{NaCl}$ on SAP appearance was different (Table 1). The mild stress induced by $\mathrm{KCl}$ raises the number of SAPs $24 \mathrm{~h}^{-1}$ plant $^{-1}$ in a statistically significant way, while $\mathrm{NaCl}$ slightly increases this value. The strong stress caused by $\mathrm{NaCl}$ and $\mathrm{KCl}$ keeps SAPs at a control level. This shows that only the mild stress induced by $\mathrm{KCl}$ increases the appearance of SAPs in sunflower seedlings. Potassium ions are an important part of the mechanism of maintaining the excitability of the cell membrane and we can assume that its slight increase in the environment affects the membrane transport (Trebacz et al., 1989, 1994; Shabala, 2003; Johansson et al., 2006; Shabala and Cuin, 2008; Shabala and Pottosin, 2014; Salvador-Recatala, 2016). The mild stress induced by $\mathrm{NaCl}$ slightly increases the number of SAPs and increases SAP velocity in a statistically significant way. An increase in SAP velocity occurs also in strong stress induced by $\mathrm{KCl}$. It is presumed that both these effects are due to the involvement of $\mathrm{K}^{+}$and $\mathrm{Na}^{+}$ions in membrane transport and the function of cation channels. The increased velocity of SAP propagation is in accordance with the cable theory, which postulates such an effect after lowering of the external (apoplast) electrical resistance caused by the applied ions.

Additionally, we have shown changes in the growth and intensity of the endogenous movement of the hypocotyl in 
spontaneously excited seedlings. The complete lack of SAPs in distilled water and D-sorbitol (with an ability to generate Gluinduced APs) growing seedlings with strongly inhibited $\mathrm{CN}$ may be associated with $\mathrm{CN}$ inhibition. In our recent work, the relationship between SAPs and $\mathrm{CN}$ was shown, i.e., the number of SAPs decreased with the restricted CN (Stolarz and Dziubinska, 2017). On the other hand, the similarly circumnutating seedlings had a significantly lower number of SAPs in the strong salt stress [4 \pm 1 SAPs $24 \mathrm{~h}^{-1}$ plant $\left.^{-1}(n=8)\right]$ than in the mild salt stress $\left[10 \pm 2\right.$ SAPs $24 \mathrm{~h}^{-1}$ plant $\left.^{-1}(n=12)\right]$. This confirms a possible complex relation between endogenous APs and endogenous hypocotyl movements in sunflower seedlings.

\section{Osmotically and Salt-Induced Series of Action Potential in 3-Week Old Sunflower}

A treatment with $\mathrm{KCl}$ combined with prior pricking induced series of APs in C. conicum (Favre et al., 1999) and A. thaliana (Favre et al., 2011). Recently, Salvador-Recatala (2016) used $\mathrm{NaCl}$ and $\mathrm{KCl}$ solutions to evoke depolarization of root cells of A. thaliana. The salts were also administered in Vicia faba and Hordeum vulgare to evoke system potentials (SPs) (Zimmermann et al., 2009). An electrical response after the hypo- or hyperosmotic solution injection (Figure 3, Table 3, Supplementary Figure S3) was dependent on the kind of treatment. Usually, a series of APs appeared, but we assume that some of the recorded spikes (Figure 3, electrode 3 and 4) are SPs. A similar recording was shown in Vicia faba, Hordeum vulgare, and Nicotiana tabacum after wounding as well as abiotic and biotic stress (Zimmermann et al., 2009, 2016). The injection of $\mathrm{NaCl}$ did not evoke series of APs (Supplementary Figure S3). It is probable that the presence of $\mathrm{K}^{+}$(but not $\mathrm{Na}^{+}$) decreases the membrane potential difference and the excitation threshold, which facilitates the generation of APs.

In this study, osmotically driven APs propagating for many centimeters along the sunflower stem have been shown for the first time. Moreover, we have shown that not only salt stimuli but also distilled water and osmotically active solutions (D-sorbitol) induce electrical signals propagating along stem.

Our working hypothesis is that osmotically active solutions and salt solutions affect membrane transport and thus evoke propagated electrical signals and changes in CN. APs could result from adjustment of membrane polarization of some cells over the threshold by ions $\left(\mathrm{K}^{+}, \mathrm{Na}^{+}\right.$, and $\left.\mathrm{Cl}^{-}\right)$contained in the solutions (in the nutrient or injected). At first, the salt stress affected the membrane transport (Foster and Miklavcic, 2015) via primary active proton pumps, secondary active antiporters and symporters, as well as passive ion channels. High salinity inhibits also plant growth via increasing osmotic pressure disrupting the plant ability to take up water and hence nutrients. Next, accumulation of salt ions (usually $\mathrm{Na}^{+}$) leads to concentrations that are toxic (Munns and Tester, 2008). The maintenance of a high cytosolic $\mathrm{K}^{+} / \mathrm{Na}^{+}$ratio appears to be critical to plant salt tolerance (Shabala and Cuin, 2008). Exposure to high concentrations of $\mathrm{Na}^{+}$can also disrupt the homeostasis of $\mathrm{K}^{+}$, which is essential for many physiological processes including excitability and organ movement.

\section{Strong but Not Mild Salt Stress Decreases Glu-Induced Series of APs}

Besides ions, nitrogen is a major factor of plant growth (Debouba et al., 2006). The sensitivity to nitrogen sources in soil and capability of nitrogen uptake are basic features of growing plants. Glutamate is a major amino acid involved both in nitrogen metabolism and in nitrogen signaling (Forde and Lea, 2007; Mousavi et al., 2013). Previously, we showed that lithium modulated Glu-induced excitability and $\mathrm{CN}$ in sunflower seedlings (Stolarz et al., 2015). Thus, we expected that also the external concentration of $\mathrm{K}, \mathrm{Na}$, and $\mathrm{Cl}$ could modulate the Gluinduced series of APs. Here, we have shown for the first time the modulation of Glu-induced excitation by salinity. Seedlings growing in distilled water did not generate SAPs under 3-day observations (Table 1), but these plants were able to generate Glu-induced series of APs (Figure 2D, Table 2). Strong salt stress disturbed significantly the Glu-induced series of APs (Figure 2D, Table 2). Thus, it has been shown that only strong salt stress, but not osmotic stress, decreased Glu-induced series of APs. These results suggested that Glu-induced APs could be a part of the signaling pathway in nitrogen metabolism.

\section{CONCLUSIONS}

Ions are important components of the cytoplasm and vacuole of living cells; therefore, their content in the environment as well as sensing and acquisition by plants is essential for survival. Potassium, chlorine, and sodium are crucial for plasma membrane potential maintenance and thus excitability of organisms, cell volume, growth, and movements. We have demonstrated the physiological impact of osmotic and salt stress on electrical signal induction and propagation as well as on $\mathrm{CN}$ and elongation of hypocotyls in whole $H$. annuus plants. Identification of SAPs accompanying varied $\mathrm{CN}$ vigor in seedlings growing in the hydroponic medium opens a new avenue for studying the relation between plant excitability and movements under different environment nutrient condition.

\section{AUTHOR CONTRIBUTIONS}

MS designed and carried out the experiments, collected, and analyzed the results, and wrote the manuscript. HD helped in the analysis of the results and editing the manuscript.

\section{SUPPLEMENTARY MATERIAL}

The Supplementary Material for this article can be found online at: https://www.frontiersin.org/articles/10.3389/fpls.2017. 01766/full\#supplementary-material 


\section{REFERENCES}

Aleman, F., Nieves-Cordones, M., Martinez, V., and Rubio, F. (2011). Root $\mathrm{K}^{+}$ acquisition in plants: the Arabidopsis thaliana model. Plant Cell Physiol. 52, 1603-1612. doi: 10.1093/pcp/pcr096

Ashley, M. K., Grant, M., and Grabov, A. (2006). Plant responses to potassium deficiencies: a role for potassium transport proteins. J. Exp. Bot. 57, 425-436. doi: $10.1093 /$ jxb/erj034

Binder, B. M., O'Malley, R. C., Wang, W., Zutz, T. C., and Bleecker, A. B. (2006). Ethylene stimulates nutations that are dependent on the ETR1 receptor. Plant Physiol. 142, 1690-1700. doi: 10.1104/pp.106.087858

Buda, A., Zawadzki, T., Krupa, M., Stolarz, M., and Okulski, W. (2003). Daily and infradian rhythms of circumnutation intensity in Helianthus annuus. Physiol. Plant. 119, 582-589. doi: 10.1046/j.1399-3054.2003.00198.x

Ceccoli, G., Bustos, D., Ortega, L. I., Senn, M. E., Vegetti, A., and Taleisnik, E. (2015). Plasticity in sunflower leaf and cell growth under high salinity. Plant Biol. 17, 41-51. doi: 10.1111/plb.12205

Charzewska, A., and Zawadzki, T. (2006). Circadian modulation of circumnutation length, period, and shape in Helianthus annuus. J. of Plant Growth Regul. 25, 324-331. doi: 10.1007/s00344-006-0042-5

Coskun, D., Britto, D. T., Kochian, L. V., and Kronzucker, H. J. (2016). How high do ion fluxes go? A re-evaluation of the two-mechanism model of $\mathrm{K}+$ transport in plant roots. Plant Sci. 243, 96-104. doi: 10.1016/j.plantsci.2015. 12.003

Darwin, C., and Darwin, F. (1880). The Power of Movement in Plants. London: John Murray

Debouba, M., Gouia, H., Valadier, M. H., Ghorbel, M. H., and Suzuki, A. (2006). Salinity-induced tissue-specific diurnal changes in nitrogen assimilatory enzymes in tomato seedlings grown under high or low nitrate medium. Plant Physiol. Bioch. 44, 409-419. doi: 10.1016/j.plaphy.2006.06.017

Dreyer, I., and Uozumi, N. (2011). Potassium channels in plant cells. FEBS J. 278, 4293-4303. doi: 10.1111/j.1742-4658.2011.08371.x

Dziubinska, H. (2003). Ways of signal transmission and physiological role of electrical potentials in plants. Acta Soc. Bot. Pol. 72, 309-318. doi: 10.5586/asbp.2003.040

Dziubinska, H., Trebacz, K., and Zawadzki, T. (2001). Transmission route for action potentials and variation potentials in Helianthus annuus L. J. Plant Physiol. 158, 1167-1172. doi: 10.1078/S0176-1617(04)70143-1

Erdei, L., Szegletes, Z., Barabas, K. N., Pestenacz, A., Fulop, K., Kalmar, L., et al. (1998). Environmental stress and the biological clock in plants: changes of rhythmic behavior of carbohydrates, antioxidant enzymes and stomatal resistance by salinity. J. Plant. Physiol. 152, 265-271. doi: 10.1016/S0176-1617(98)80141-7

Favre, P., Greppin, H., and Degli Agosti, R. (2011). Accession-dependent action potentials in Arabidopsis. J. Plant Physiol. 168, 653-660. doi: 10.1016/j.jplph.2010.09.014

Favre, P., Zawadzki, T., Dziubinska, H., Trebacz, K., Greppin, H., and Degli Agosti, R. (1999). Repetitive action potentials induced in the liverwort Conocephalum conicum (L.). Arch. Sci. 52, 187-198.

Forde, B. G., and Lea, P. J. (2007). Glutamate in plants: metabolism, regulation, and signalling. J. Exp. Bot. 58, 2339-2358. doi: 10.1093/jxb/erm121

Foster, K. J., and Miklavcic, S. J. (2015). Toward a biophysical understanding of the salt stress response of individual plant cells. J. Theor. Biol. 385, 130-142. doi: 10.1016/j.jtbi.2015.08.024

Grefen, C., Honsbein, A., and Blatt, M. R. (2011). Ion transport, membrane traffic and cellular volume control. Curr. Opin. Plant. Biol. 14, 332-339. doi: 10.1016/j.pbi.2011.03.017

Hayashi, Y., Nishiyama, H., Tanoi, K., Ohya, T., Nihei, N., Tanioka, K., et al. (2004). An aluminum influence on root circumnutation in dark revealed by a new super-HARP (high-gain avalanche rushing amorphous photoconductor) camera. Plant Cell Physiol. 45, 351-356. doi: 10.1093/pcp/pch042

Hedrich, R., Salvador-Recatala, V., and Dreyer, I. (2016). Electrical wiring and long-distance plant communication. Trends Plant Sci. 21, 376-387. doi: 10.1016/j.tplants.2016.01.016

Hinrichsen, R. D., Belsky, D., Jones, L. A., and Mialki, R. (2012). The frequency of the spontaneous behavioral response in Paramecium tetraurelia is simultaneously modulated by both ultradian and circadian rhythms. Biol. Rhythm Res. 41, 1-14. doi: 10.1080/09291016.2012.692254
Inoue, N., Arase, T., Hagiwara, M., Amano, T., Hayashi, T., and Ikeda, R. (1999). Ecological significance of root tip rotation for seedling establishment of Oryza sativa L. Ecol. Res. 14, 31-38. doi: 10.1046/j.1440-1703.1999.141282.x

Johansson, I., Wulfetange, K., Porée, F., Michard, E., Gajdanowicz, P., Lacombe, B., et al. (2006). External $\mathrm{K}^{+}$modulates the activity of the Arabidopsis potassium channel SKOR via an unusual mechanism. Plant J. 46, 269-281. doi: 10.1111/j.1365-313X.2006.02690.x

Johnsson, A. (1979). "Circumnutation," in Encyclopedia of Plant Physiology. Physiology of Movements, eds W. Haupt and E. Feinleib (Berlin: Springer), 627-646.

Johnsson, A. (1997). Circumnutations: results from recent experiments on Earth and in space. Planta 203, 147-158. doi: 10.1007/PL00008103

Kiep, V., Vadassery, J., Lattke, J., Maaß, J.-P., Boland, W., Peiter, E., et al. (2015). Systemic cytosolic $\mathrm{Ca}^{2+}$ elevation is activated upon wounding and herbivory in Arabidopsis. New Phytol. 207, 996-1004. doi: 10.1111/nph.13493

Koselski, M., Dziubinska, H., Seta-Koselska, A., and Trebacz, K. (2015). A nitrate-permeable ion channel in the tonoplast of the moss Physcomitrella patens. Planta 241, 1207-1219. doi: 10.1007/s00425-015-2 250-3

Koselski, M., Trebacz, K., and Dziubinska, H. (2017). Vacuolar ion channels in the liverwort Marchantia polymorpha: influence of ion channel inhibitors. Planta 245, 1049-1060. doi: 10.1007/s00425-017-2661-4

Kosuge, K., Iida, S., Katou, K., and Mimura, T. (2013). Circumnutation on the water surface: female flowers of Vallisneria. Sci. Rep. 3:1133. doi: 10.1038/srep01133

Krol, E., Dziubinska, H., Stolarz, M., and Trebacz, K. (2006). Effects of ion channel inhibitors on cold- and electrically-induced action potentials in Dionaea muscipula. Biol. Plant. 50, 411-416. doi: 10.1007/s10535-006-0058-5

Król, E., Dziubinska, H., and Trebacz, K. (2010). "What do plants need action potentials for?" in Action Potential, ed M. L. DuBois (New York, NY: Nova Science Publisher), 1-28.

Krol, E., Dziubinska, H., Trebacz, K., Koselski, M., and Stolarz, M. (2007). The influence of glutamic and aminoacetic acids on the excitability of the liverwort Conocephalum conicum. J. Plant Physiol. 164, 773-784. doi: 10.1016/j.jplph.2006.04.015

Kurenda, A., Stolarz, M., and Zdunek, A. (2015). Electrical potential oscillations movement relations in circumnutating sunflower stem and effect of ion channel and proton pump inhibitors on circumnutation. Physiol. Plant. 153, 307-317. doi: $10.1111 / \mathrm{ppl} .12277$

Larson, K. C. (2000). Circumnutation behavior of an exotic honeysuckle vine and its native congener: influence on clonal mobility. Am. J. Bot. 87, 533-538. doi: $10.2307 / 2656597$

Lloyd, D. (2006). Ultradian rhythms and clocks in plants and yeast. Biol. Rhythm Res. 37, 281-296. doi: 10.1080/09291010600804379

Maathuis, F. J. (2014). Sodium in plants: perception, signalling, and regulation of sodium fluxes. J. Exp. Bot. 65, 849-858. doi: 10.1093/jxb/ert326

Macedo, F. C. O., Dziubinska, H., Trebacz, K., Oliveira, R. F., and Moral, R. A. (2015). Action potentials in abscisic acid-deficient tomato mutant generated spontaneously and evoked by electrical stimulation. Acta Physiol. Plant. 37, 207. doi: 10.1007/s11738-015-1950-4

Migliaccio, F., Tassone, P., and Fortunati, A. (2013). Circumnutation as an autonomous root movement in plants. Am. J. Bot. 100, 4-13. doi: 10.3732/ajb.1200314

Millet, B., and Badot, P. (1996). "The revolving movement mechanism in Phaseolus; New approaches to old questions," in Vistas on Biorhythmicity, eds H. Greppin, R. Degli Agosti, and M. Bonzon (Geneva: University of Geneva), 77-98.

Mousavi, S. A., Chauvin, A., Pascaud, F., Kellenberger, S., and Farmer, E. E. (2013). Glutamate receptor-like genes mediate leaf-to-leaf wound signalling. Nature 500, 422-426. doi: 10.1038/nature12478

Mukherjee, S., David, A., Yadav, S., Baluska, F., and Bhatla, S. C. (2014). Salt stressinduced seedling growth inhibition coincides with differential distribution of serotonin and melatonin in sunflower seedling roots and cotyledons. Physiol. Plant. 152, 714-728. doi: 10.1111/ppl.12218

Munns, R., and Tester, M. (2008). Mechanisms of salinity tolerance. Annu. Rev. Plant Biol. 59, 651-681. doi: 10.1146/annurev.arplant.59.032607.092911

Paszewski, A., and Zawadzki, T. (1973). Action potentials in Lupinus angustifolius shoots. J. Exp. Bot. 24, 804-809. doi: 10.1093/jxb/24.5.804 
Paszewski, A., and Zawadzki, T. (1974). Action potentials in Lupinus angustifolius shoots. 2. Determination of strength-duration relation and all-or-nothing law. J. Exp. Bot. 25, 1097-1103. doi: 10.1093/jxb/25.6.1097

Paszewski, A., and Zawadzki, T. (1976a). Action potentials in Lupinus angustifolius shoots. 3. Determination of refractory periods. J. Exp. Bot. 27, 369-374.

Paszewski, A., and Zawadzki, T. (1976b). Action potentials in Lupinus angustifolius shoots. 4. Application of thermal stimuli and investigations on conduction pathways of. J. Exp. Bot. 27, 859-863.

Salvador-Recatala, V. (2016). The AKT2 potassium channel mediates $\mathrm{NaCl}$ induced depolarization in the root of Arabidopsis thaliana. Plant Signal. Behav. 11:e1165381. doi: 10.1080/15592324.2016.1165381

Salvador-Recatala, V., and Tjallingii, W. F. (2015). A new application of the electrical penetration graph (EPG) for acquiring and measuring electrical signals in phloem sieve elements. J. Vis. Exp. e52826. doi: 10.3791/52826

Salvador-Recatala, V., Tjallingii, W. F., and Farmer, E. E. (2014). Realtime, in vivo intracellular recordings of caterpillar-induced depolarization waves in sieve elements using aphid electrodes. New Phytol. 203, 674-684. doi: $10.1111 /$ nph. 12807

Shabala, S. (2000). Ionic and osmotic components of salt stress specifically modulate net ion fluxes from bean leaf mesophyll. Plant Cell. Environ. 23, 825-837. doi: 10.1046/j.1365-3040.2000.00606.x

Shabala, S. (2003). Physiological implications of ultradian oscillations in plant roots. Plant Soil 255, 217-226. doi: 10.1023/A:1026198927712

Shabala, S., and Cuin, T. A. (2008). Potassium transport and plant salt tolerance. Physiol. Plant. 133, 651-669. doi: 10.1111/j.1399-3054.2007.01008.x

Shabala, S., and Knowles, A. (2002). Rhythmic patterns of nutrient acquisition by wheat roots. Funct Plant Biol. 29, 595-605. doi: 10.1071/PP01130

Shabala, S. N., and Newman, I. A. (1997). Proton and calcium flux oscillations in the elongation region correlate with root nutation. Physiol. Plant. 100, 917-926. doi: 10.1111/j.1399-3054.1997.tb00018.x

Shabala, S., and Pottosin, I. (2014). Regulation of potassium transport in plants under hostile conditions: implications for abiotic and biotic stress tolerance. Physiol. Plant. 151, 257-279. doi: 10.1111/ppl.12165

Shabala, S., Wu, H. H., and Bose, J. (2015). Salt stress sensing and early signalling events in plant roots: current knowledge and hypothesis. Plant Sci. 241, 109-119. doi: 10.1016/j.plantsci.2015.10.003

Sibaoka, T. (1991). Rapid plant movements triggered by action potentials. Bot. Mag. Tokyo 104, 73-95. doi: 10.1007/BF02493405

Singh, N., and Bhatla, S. C. (2016). Nitric oxide and iron modulate heme oxygenase activity as a long distance signaling response to salt stress in sunflower seedling cotyledons. Nitric Oxide 53, 54-64. doi: 10.1016/j.niox.2016.01.003

Spurny, M. (1968). Effect of root tip amputation on spiral oscillations of growing hypocotyl with radicle of pea (Pisum sativum L.). Biol. Plant. 10, 98-111. doi: 10.1007/BF02921024

Spurny, M. (1975). Elongation and circumnutation oscillations of hypocotyl of pine seedlings (Pinus silvestris L.). Biol Plant. 17, 43-49. doi: 10.1007/BF02921073

Stahlberg, R., Stephens, N. R., Cleland, R. E., and Van Volkenburgh, E. (2006). Shade-induced action potentials in Helianthus annuus L. Originate Primarily from the Epicotyl. Plant Signal. Behav. 1, 15-22. doi: 10.4161/psb.1.1.2275

Stankovic, B., Witters, D. L., Zawadzki, T., and Davies, E. (1998). Action potentials and variation potentials in sunflower: an analysis of their relationships and distinguishing characteristics. Physiol. Plant. 103, 51-58. doi: 10.1034/j.1399-3054.1998.1030107.x

Stolarz, M. (2009). Circumnutation as a visible plant action and reaction: physiological, cellular and molecular basis for circumnutations. Plant. Signal. Behav. 4, 380-387. doi: 10.4161/psb.4.5.8293

Stolarz, M., and Dziubinska, H. (2017). Spontaneous action potentials and circumnutation in Helianthus annuus. Acta Physiol. Plant. 39, 234 doi: 10.1007/s11738-017-2528-0

Stolarz, M., Dziubinska, H., Krupa, M., Buda, A., Trebacz, K., and Zawadzki, T. (2003). Disturbances of stem circumnutations evoked by wound-induced variation potentials in Helianthus annuus L. Cell. Mol. Biol. Lett. 8, 31-40.

Stolarz, M., Król, E., and Dziubinska, H. (2015). Lithium distinguishes between growth and circumnutation and augments glutamate-induced excitation of Helianthus annuus seedlings. Acta Physiol. Plant. 37, 1-9. doi: $10.1007 / \mathrm{s} 11738-015-1814-\mathrm{y}$
Stolarz, M., Krol, E., Dziubinska, H., and Kurenda, A. (2010). Glutamate induces series of action potentials and a decrease in circumnutation rate in Helianthus annuus. Physiol. Plant. 138, 329-338. doi: 10.1111/j.1399-3054.2009.0 1330.x

Stolarz, M., Krol, E., Dziubinska, H., and Zawadzki, T. (2008). Complex relationship between growth and circumnutations in Helianthus annuus stem. Plant Signal. Behav. 3, 376-380. doi: 10.4161/psb.3.6.5714

Stolarz, M., Zuk, M., Krol, E., and Dziubinska, H. (2014). Circumnutation Tracker: novel software for investigation of circumnutation. Plant Methods 10:24. doi: 10.1186/1746-4811-10-24

Szczerba, M. W., Britto, D. T., and Kronzucker, H. J. (2009). $\mathrm{K}^{+}$transport in plants: physiology and molecular biology. J. Plant Physiol. 166, 447-466. doi: 10.1016/j.jplph.2008.12.009

Trebacz, K. (1992). Measurements of intracellular and extracellular $\mathrm{pH}$ in the liverwort Conocephalum conicum during action potentials. Physiol. Plant. 84, 448-452. doi: 10.1111/j.1399-3054.1992.tb04689.x

Trebacz, K., Schonknecht, G., Dziubinska, H., and Hanaka, A. (2007). Characteristics of anion channels in the tonoplast of the liverwort Conocephalum conicum. Plant Cell. Physiol. 48, 1747-1757. doi: $10.1093 / \mathrm{pcp} / \mathrm{pcm} 147$

Trebacz, K., Simonis, W., and Schonknecht, G. (1994). Cytoplasmic $\mathrm{Ca}^{2+}$, $\mathrm{K}^{+}, \mathrm{CL}^{-}$, and $\mathrm{NO}^{3}$ - activities in the liverwort Conocephalum conicum at rest and during action potentials. Plant Physiol. 106, 1073-1084. doi: 10.1104/pp.106.3.1073

Trebacz, K., Tarnecki, R., and Zawadzki, T. (1989). The effects of ionic channel inhibitors and factors modifying metabolism on the excitability of the liverwort Conocephalum conicum. Physiol. Plant. 75, 24-30. doi: 10.1111/j.1399-3054.1989.tb02058.x

Trebacz, K., and Zawadzki, T. (1985). Light triggered action potentials in the liverwort Conocephalum conicum. Physiol. Plant. 64, 482-486. doi: 10.1111/j.1399-3054.1985.tb08526.x

Ueda, A., Kathiresan, A., Inada, M., Narita, Y., Nakamura, T., Shi, W. M., et al. (2004). Osmotic stress in barley regulates expression of a different set of genes than salt stress does. J. Exp. Bot. 55, 2213-2218. doi: 10.1093/jxb/erh242

van Bel, A. J. E., Furch, A. C. U., Will, T., Buxa, S. V., Musetti, R., and Hafke, J. B. (2014). Spread the news: systemic dissemination and local impact of Ca-2 signals along the phloem pathway. J. Exp. Bot. 65, 1761-1787. doi: $10.1093 / \mathrm{jxb} / \mathrm{ert} 425$

White, P. (2001). Chloride in soils and its uptake and movement within the plant: a review. Ann. Bot. 88, 967-988. doi: 10.1006/anbo.2001.1540

Wu, G. Q., Feng, R. J., Liang, N., Yuan, H. J., and Sun, W. B. (2015a). Sodium chloride stimulates growth and alleviates sorbitol-induced osmotic stress in sugar beet seedlings. Plant Growth Regul. 75, 307-316. doi: 10.1007/s10725-014-9954-4

Wu, G. Q., Jiao, Q., and Shui, Q. Z. (2015b). Effect of salinity on seed germination, seedling growth, and inorganic and organic solutes accumulation in sunflower (Helianthus annuus L.). Plant Soil Environ. 61, 220-226. doi: 10.17221/22/2015-PSE

Yoshihara, T., and Iino, M. (2005). Circumnutation of rice coleoptiles: its occurrence, regulation by phytochrome, and relationship with gravitropism. Plant Cell Environ. 28, 134-146. doi: 10.1111/j.1365-3040.2004.0 1249.x

Zachariassen, E., and Johnsson, A. (1988). Effects of lithum ions on the circumnutations of Helianthus hypocotyls. Physiol. Plant. 72, 147-152. doi: 10.1111/j.1399-3054.1988.tb06636.x

Zawadzki, T. (1979). Electrical properties of Lupinus angustifolius L. stem.1. Sub-threshold potentials. Acta Soc. Bot. Pol. 48, 99-107. doi: 10.5586/asbp. 1979.009

Zawadzki, T. (1980). Action potentials in Lupinus angustifolius shoots. 5. Spread of excitation in the stem, leaves, and root. J. Exp. Bot. 31, 1371-1377. doi: $10.1093 / \mathrm{jxb} / 31.5 .1371$

Zawadzki, T., Davies, E., Dziubinska, H., and Trebacz, K. (1991). Characteristics of action potentials in Helianthus annuus. Physiol. Plant. 83, 601-604. doi: 10.1111/j.1399-3054.1991.tb02475.x

Zawadzki, T., Dziubinska, H., and Davies, E. (1995). Characteristics of action potentials generated spontaneously in Helianthus annuus. Physiol. Plant. 93, 291-297. doi: 10.1111/j.1399-3054.1995.tb02231.x 
Zhu, J. K. (2003). Regulation of ion homeostasis under salt stress. Curr. Opin. Plant Biol. 6, 441-445. doi: 10.1016/S1369-5266(03)00085-2

Zimmermann, M. R., Maischak, H., Mithöfer, A., Boland, W., and Felle, H. H. (2009). System potentials, a novel electrical long-distance apoplastic signal in plants, induced by wounding. Plant Physiol. 149, 1593-1600. doi: $10.1104 /$ pp.108.133884

Zimmermann, M. R., Mithöfer, A., Will, T., Felle, H. H., and Furch, A. C. U. (2016). Herbivore triggered electrophysiological reactions: candidates for systemic signals in higher plants and the challenge of their identification. Plant Physiol. 170, 2407-2419. doi: 10.1104/pp.15.01736
Conflict of Interest Statement: The authors declare that the research was conducted in the absence of any commercial or financial relationships that could be construed as a potential conflict of interest.

Copyright $\odot 2017$ Stolarz and Dziubinska. This is an open-access article distributed under the terms of the Creative Commons Attribution License (CC BY). The use, distribution or reproduction in other forums is permitted, provided the original author(s) or licensor are credited and that the original publication in this journal is cited, in accordance with accepted academic practice. No use, distribution or reproduction is permitted which does not comply with these terms. 